FINAL REPORT

U.S. Department of Energy

\title{
A NOVEL ENERGY EFFICIENT PLASMA CHEMICAL PROCESS FOR THE DESTRUCTION OF VOLATILE TOXIC COMPOUNDS
}

$\begin{array}{ll}\text { Principal Investigator: } & \text { Lal A. Pinnaduwage } \\ & \text { Oak Ridge National Laboratory, Oak Ridge, TN }\end{array}$

Collaborators: Cheung-Yu Ma

Oak Ridge National Laboratory, Oak Ridge, TN

Dennis L. McCorkle

University of Tennessee, Knoxville, TN

Project ID: 54973

Grant Project Officers: $\quad$ Dr. Robert Price (SC)

Mr. Chester E. Miller (EM)

Project Duration: October 1, 1996 to March 31, 2000 


\section{TABLE OF CONTENTS}

A. EXECUTIVE SUMMARY $\ldots \ldots \ldots \ldots \ldots \ldots \ldots \ldots \ldots \ldots \ldots \ldots \ldots \ldots$

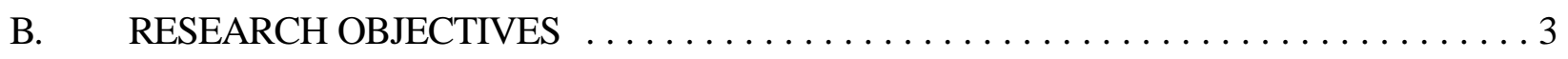

C. METHODS AND RESULTS $\ldots \ldots \ldots \ldots \ldots \ldots \ldots \ldots \ldots \ldots \ldots \ldots \ldots \ldots$

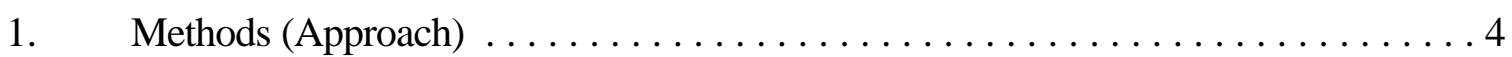

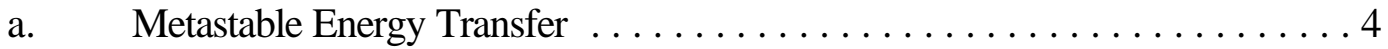

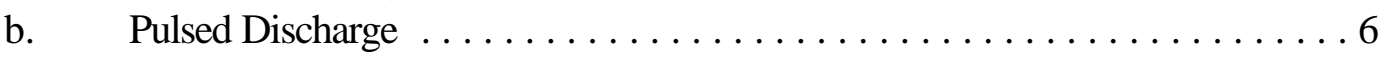

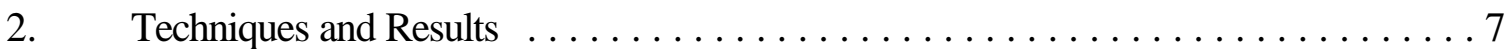

a. Basic Studies . . . . . . . . . . . . . . . . . . . . . . 7

b. Plasma Remediation Experiments $\ldots \ldots \ldots \ldots \ldots \ldots \ldots \ldots \ldots$

D. RELEVANCE, IMPACT, AND TECHNOLOGY TRANSFER $\ldots \ldots \ldots \ldots \ldots$

a. Treatment of Highly-Contaminated Water and Soil ............ 12

b. Secondary Stage of a Thermal Incinerator . . . . . . . . . . . . . . 13

c. Enhancement of Basic Knowledge on Low-Temperature Plasmas . . . . . . 14

E. PROJECT PRODUCTIVITY $\ldots \ldots \ldots \ldots \ldots \ldots \ldots \ldots \ldots \ldots \ldots \ldots \ldots \ldots$

F. PERSONNEL ASSOCIATED WITH THE PROJECT $\ldots \ldots \ldots \ldots \ldots \ldots \ldots \ldots \ldots$

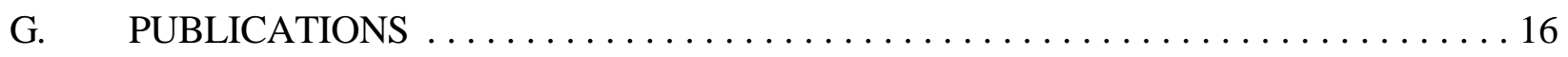

a. Peer-Reviewed Publications $\ldots \ldots \ldots \ldots \ldots \ldots \ldots \ldots \ldots \ldots \ldots$

b. Full Papers Published in Conference Proceedings . . . . . . . . . . . 17

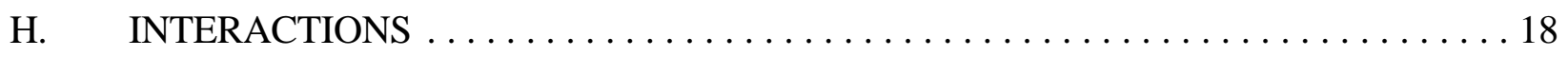

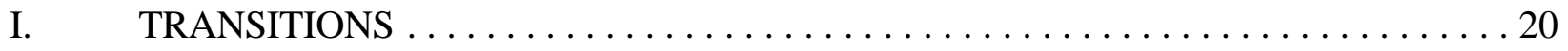

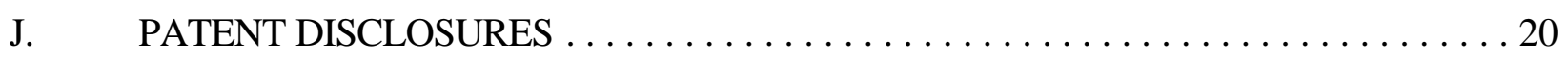

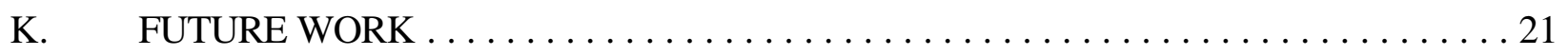

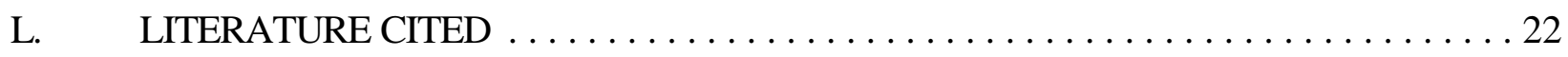




\section{A. EXECUTIVE SUMMARY}

During the past three years, we have conducted a feasibility study on a novel plasma chemical process for the destruction of low-concentrations (below several percent) of toxic volatile compounds from contaminated air streams. Such contaminated air streams are encountered at the DOE waste sites in the following instances: (i) off-gases resulting from air-stripping of highly-contaminated water and soil (contaminated with DNAPLs, VOCs, etc), (ii) effluent from the incineration of highlyconcentrated combustible hazardous wastes. If the contaminated air stream has concentrations of a few parts per million (ppm) then passive methods, such as activated carbon, can be used successfully. If the concentration level is more than several percent, then thermal incineration can be successfully used. However, in the intermediate range neither of the above processes are suitable. During the past decade or so, non-thermal plasma techniques have been investigated for the remediation of waste streams with concentrations in this intermediate range.

Our novel non-thermal plasma technique was based on extremely large cross sections that had been discovered at the Oak Ridge National Laboratory for dissociative attachment of electrons to highly-excited states of molecules. In these original basic studies, molecular excitation was achieved using lasers. During the present project we have conducted studies to show that molecular excitation can be achieved inexpensively by using two different glow discharge based processes, and have conducted basic studies to clarify the mechanisms involved. We also built a "bench-top" plasma reactor and illustrated that this new knowledge can be successfully applied to the remediation of dilute concentrations of toxic gas streams. One of the key features of our technique is to "zero in" on target 
gases without wasting energy on the bulk of the carrier gases.

Up to now we have conducted studies on two target gases (benzene and methylene chloride) where we used inert gases (such as $\mathrm{Ar}$ and $\mathrm{He}$ ) and $\mathrm{N}_{2}$ as carrier gases. Our studies have shown that inert gases enhance the excited state formation process, and that there are several attractive features associated with our technique. For example, no hazardous gaseous byproducts were observed at the reactor output, and hence even the use of inert gases may be economical in the case of stripping of contaminated soil or water with inert gases, since the output can be recycled. In the future, if funding is available, we hope to investigate the effect of replacing inert gases in our experiments with air -- $\mathrm{N}_{2}$, $\mathrm{O}_{2}$, and water vapor in representative concentrations--, which will determine whether our approach will be suitable for the second stage of incinerators and in the air stripping of contaminated water/soil. This research was conducted in collaboration with the University of Tennessee, Knoxville. A graduate student working towards his doctoral degree worked on some of the experiments related to the project, but was not supported by the project.

This research project resulted in 9 refereed journal publications. (Most of the papers were published in 1999, as it took us a considerable amount of time to set up the apparatuses from ground zero, and to develop the experimental techniques). Another paper has been submitted, and we have sufficient material to write yet another paper based on the studies conducted during the last two months. The results of our studies have been presented at 18 conferences and workshops, and 4 of these presentations have been published as full papers in conference proceedings. Two patent disclosures have been accepted to be filed by the Office of Technology Transfer at the Oak Ridge National Laboratory. 


\section{B. RESEARCH OBJECTIVES}

Destruction of low-concentrations (below several percent) of toxic volatile compounds from contaminated air stream is encountered at the DOE waste sites in the following instances: (i) off-gases resulting from air-stripping of highly-contaminated water and soil (contaminated with DNAPLs, VOCs, etc), (ii) effluent from the incineration of highly-concentrated combustible hazardous wastes. If the contaminated air stream has concentrations of a few parts per million (ppm) then passive methods, such as activated carbon, can be used successfully. If the concentration level is more than several percent, then thermal incineration can be successfully used. However, in the intermediate range neither of the above processes are suitable [1]. During the past decade or so, non-thermal plasma techniques have been investigated (see the references in $[1,2]$ ) for the remediation of waste streams with concentrations in this intermediate range (to our knowledge, our project was the only one that addressed this problem under the EMSP sponsorship). Our approach is a completely different from those previous non-thermal plasma techniques.

The main objective was to investigate the feasibility of a novel plasma chemical process for the remediation of toxic gas mixtures based on an enhanced dissociative electron attachment process that had been discovered in a basic research program: Prior to this project, it had been found that molecules excited to highly-excited states via laser irradiation efficiently attached electrons leading to the dissociation of the molecule (see, [3-6] and references therein). The following tasks were needed to be completed during the three year duration of the project in order to illustrate the feasibility of the new technology:

1. Since the usage of lasers is not cost effective, two discharge based schemes were planned to be investigated for molecular excitation.

2. The basic mechanisms involving dissociative electron attachment to highly-excited molecules needed to be studied, in order to optimize the process.

3. A bench-top plasma reactor needed to be constructed to conduct actual plasma destruction measurements, so that the destruction efficiency could be quantified.

4. Methodologies for, (a) determination of the destruction efficiency, and (b) analysis of the byproducts 
from the reactor, needed to be developed.

5. Basic studies needed to be conducted to understand the observations of the remediation studies, and thus to enhance the remediation process.

As described below, we have accomplished these objectives, and have illustrated the feasibility of this new technology. However, further research is needed before this technology can be applied in the field.

C. METHODS AND RESULTS

\section{Methods (Approach)}

We investigated two schemes for achieving molecular excitation using glow discharges: (i) excitation transfer from the high-lying (energy around $10 \mathrm{eV}$ ) metastable states of inert gases that are efficiently produced in glow discharges, and (ii) a pulsed glow discharge. We will briefly explain the principles behind these schemes, and then the progress that we have achieved so far.

\section{a. Metastable Energy Transfer}

Metastable states of rare gases play important roles in a wide variety of systems such as laboratory plasmas, lamps, and laser discharges due to their ability to store energy and their long lifetimes [7-9]; the energies and the lifetimes of the metastable states of rare gases are shown in Table II. In a typical rare-gas plasma, the relative density of metastable to ground-state atoms is $10^{-4}$, while the degree of ionization with respect to ground-state population is only $10^{-5}$ [10]; the accumulation of number density in these long-lived states is limited only due to the fact that they are efficiently ionized via collisions with energetic electrons [9, $10]$. 
Table II. Energies and lifetimes of the metastable states of inert gases [7].

\begin{tabular}{|l|l|l|l|}
\hline $\begin{array}{l}\text { INERT } \\
\text { GAS }\end{array}$ & STATE & ENERGY(eV) & LIFETIME(s) \\
\hline $\mathrm{He}$ & $2^{1} \mathrm{~S}_{2}$ & 20.6 & 0.02 \\
& $2^{3} \mathrm{~S}_{1}$ & 19.8 & 8000 \\
\hline $\mathrm{Ne}$ & $3^{3} \mathrm{P}_{0}$ & 16.7 & 430 \\
& $3^{3} \mathrm{P}_{2}$ & 16.6 & 24 \\
\hline $\mathrm{Ar}$ & $4^{3} \mathrm{P}_{0}$ & 11.7 & 45 \\
& $4^{3} \mathrm{P}_{2}$ & 11.5 & 56 \\
\hline $\mathrm{Kr}$ & $5^{3} \mathrm{P}_{0}$ & 10.6 & 0.49 \\
& $5^{3} \mathrm{P}_{2}$ & 9.9 & 85 \\
\hline $\mathrm{Xe}$ & $6^{3} \mathrm{P}_{0}$ & 9.5 & 0.1 \\
& $6^{3} \mathrm{P}_{2}$ & 8.3 & 149 \\
\hline
\end{tabular}

Even though the "inert" gases are chemically inert in their ground states, they are highly reactive [8, $11,12]$ in their excited metastable states (which have the electronic configuration of alkali atoms). The cross sections for excitation transfer from rare gas metastable states to a wide variety of molecules lie in the range of $-10^{-16}$ to $10^{-14} \mathrm{~cm}^{2}[8,11,12]$. This is due to the fact that the oscillator strengths of molecules are large and continuous above energies starting from 1-2 eV below the ionization potential and extending to a few eV above the ionization threshold (see Fig. 2).

The excitation transfer cross sections are especially large when the ionization threshold of the "target molecule" lies close to the energy of the metastable state of the rare gas; this is due to the high congestion of the energy levels of the target molecule close to its ionization threshold. Most of the toxic volatile compounds of interest to the DOE EMSP program have ionization thresholds of $<12 \mathrm{eV}$; see the examples in Table III $[13,14]$, compared to the values of 12.1 and $15.6 \mathrm{eV}$ for $\mathrm{O}_{2}$ and $\mathrm{N}_{2}$ (the major 
constituents of air). Therefore, Ar with metastable-state energy of . $11.6 \mathrm{eV}$ can be used almost exclusively for the target-specific excitation of such component gases without wasting significant amounts of energy on the background gases. It is clear from Table III, that excitation transfer to $\mathrm{N}_{2}$ is much smaller; while the cross section for $\mathrm{O}_{2}$ is larger, that energy will not be completely wasted since the excitation of $\mathrm{O}_{2}$ with subsequent attachment of slow electrons will produce $\mathrm{O}$ and $\mathrm{O}^{-}$both of which are highly-reactive species, and thus will induce secondary reactions with target molecules.

Table III. Excitation transfer cross sections for the $\operatorname{Ar}\left({ }^{3} \mathrm{P}_{2}\right)$ metastable state for several molecules of interest [12].

\begin{tabular}{|l|c|c|}
\hline \multicolumn{1}{|c|}{ Molecule } & $\begin{array}{c}\text { Ionization } \\
\text { Threshold(eV) }\end{array}$ & $\begin{array}{c}\text { Cross Section } \\
\left(\mathrm{D}^{2}\right)\end{array}$ \\
\hline Nitrogen & 15.6 & 5 \\
\hline Oxygen & 12.1 & 29 \\
\hline Water Vapor & 12.6 & 61 \\
\hline Benzene & 9.2 & 160 \\
\hline Toluene & 8.8 & $?$ \\
\hline Carbon Tetrachloride & 11.5 & 220 \\
\hline Trichloroethylene & 9.5 & $?$ \\
\hline Methylene Chloride & 11.3 & 180 \\
\hline
\end{tabular}




\section{b. Pulsed Discharge}

Dissociative electron attachment to highly-excited states of target molecules can be achieved in a pulsed discharge of either the target gas by itself or an inert gas/target gas mixture. In a unitary gas, such excitations can occur via direct electron impact during the discharge; the Rydberg states survive in the post discharge, where they efficiently attach the slow electrons produced by the rapid cooling of the discharge electrons. The long lifetimes associated with Rydberg states is exploited in this techniques to enhance the energy efficiency of the process. In an inert gas/target gas mixture, excitation transfer from the metastable states in the post discharge will lead to a higher number density of Rydberg states of the target molecule. The combination of pulsed discharge with inert gas carrier can be expected to optimize the efficiency of the process, which has been found to be correct [15].

\section{Techniques and Results}

\section{a.. Basic Studies}

In 1997 we built a flowing plasma apparatus to conduct these studies and successfully demonstrated the validity of the concept [16-18]. In this "plasma mixing" method, metastable states produced in a DC glow discharge were transferred to an adjoining "target region" in a flow apparatus, where they were mixed with a target gas. Excited states of the target gas, produced via excitation transfer, efficiently attached electrons that were also carried to the target region by the gas flow. In these basic studies we used simple target molecules to illustrate the concept. Enhanced negative ion formation was confirmed by the reduction in electron density in the target region using a Langmuir probe [16,17], and also by laser photodetachment of negative ions [18]. These studies also confirmed a hypothesis [19] that we proposed to explain the efficient formation of $\mathrm{H}^{-}$ions in a methane plasma that had been observed by Iizuka et al. [20, 21]. 
In order to illustrate the production of Rydberg states in a pulsed discharge, we conducted a basic study on negative ion formation in pulsed discharges. Oxygen was selected as the first molecule to study due to two reasons: (i) it is a simple diatomic molecule, and thus it would be easy to clarify the electron attachment mechanisms, and (ii) it is the second most abundant molecule in air, and thus oxygen related chemistry is important for understanding the mechanisms of hazardous gas destruction and the formation of byproducts in contaminated air streams. It must be noted that electron attachment to $\mathrm{O}_{2}$ produced $\mathrm{O}$ atoms together with $\mathrm{O}^{-}$atoms, and these $\mathrm{O}$ atoms may be involved in the destruction of hazardous molecules via various chemical pathways.

Efficient production of $\mathrm{O}^{-}$ions in a pulsed glow discharge of $\mathrm{O}_{2}$ was studied in a Langmuir probe-assisted laser photodetachment experiment; the release of electrons by the detachment of $\mathrm{O}^{-}$ions by a pulsed Nd: YAG laser was monitored using a Langmuir probe, as described in [22]. In this study [22] we showed that $\mathrm{O}^{-}$ions are efficiently produced in a pulsed glow discharge of $\mathrm{O}_{2}$. While $\mathrm{O}^{-}$ions were also observed during the discharge "on" time, an enhancement in $\mathrm{O}^{-}$ion formation was observed in the afterglow period. The experimental observations were shown to be consistent with enhanced dissociative electron attachment to $\mathrm{HR}$ states of $\mathrm{O}_{2}$ produced by electron impact during the discharge "on" time. These HR states live well into the afterglow, where cooling of electrons enhance the electron attachment process; furthermore, detachment of $\mathrm{O}^{-}$ions via electron impact is avoided in the afterglow.

In addition to the above studies, we also measured electron attachment to ground states of benzene and methylene chloride. As described below, the destruction of these two molecules was studied in a plasma remediation apparatus; in order to understand the observations of those experiments, we needed to know whether they could be explained by dissociative electron attachment to the ground electronic states. Electron attachment cross section data on benzene were not available; data on electron attachment to methylene chloride were available only for electron energies below 0.8 eV [23-26]. Therefore, we studied electron attachment to both these molecules in an electron swarm apparatus. Electron attachment to the ground state of benzene was below the detection level of the electron swarm apparatus, i.e., $<10^{-12} \mathrm{~cm}^{3} \mathrm{~s}^{-1}$ for mean electron energies below $5 \mathrm{eV}$ [27]. The 
maximum electron attachment rate constant for methylene chloride was measured to be $8 \times 10^{-11}$ $\mathrm{cm}^{3} \mathrm{~s}^{-1}[28]$. These measurements were crucial for the understanding of the observations of the plasma remediation experiments discussed below.

\section{b. Plasma Remediation Experiments}

A bench-top plasma reactor was constructed in 1997 for these studies, and these studies were conducted in parallel to the basic studies described above. A schematic diagram of the apparatus is shown in Fig. 1.

All gas mixtures were made in a separate gas manifold (not shown) which consisted of a pumping system, gas handling lines, and pressure measurement gauges. Each gas mixture was left for at least a week or so to achieve equilibrium, and the concentrations were confirmed by comparing with a NIST-traceable standard gas mixture. The details of the apparatus and the procedure are described

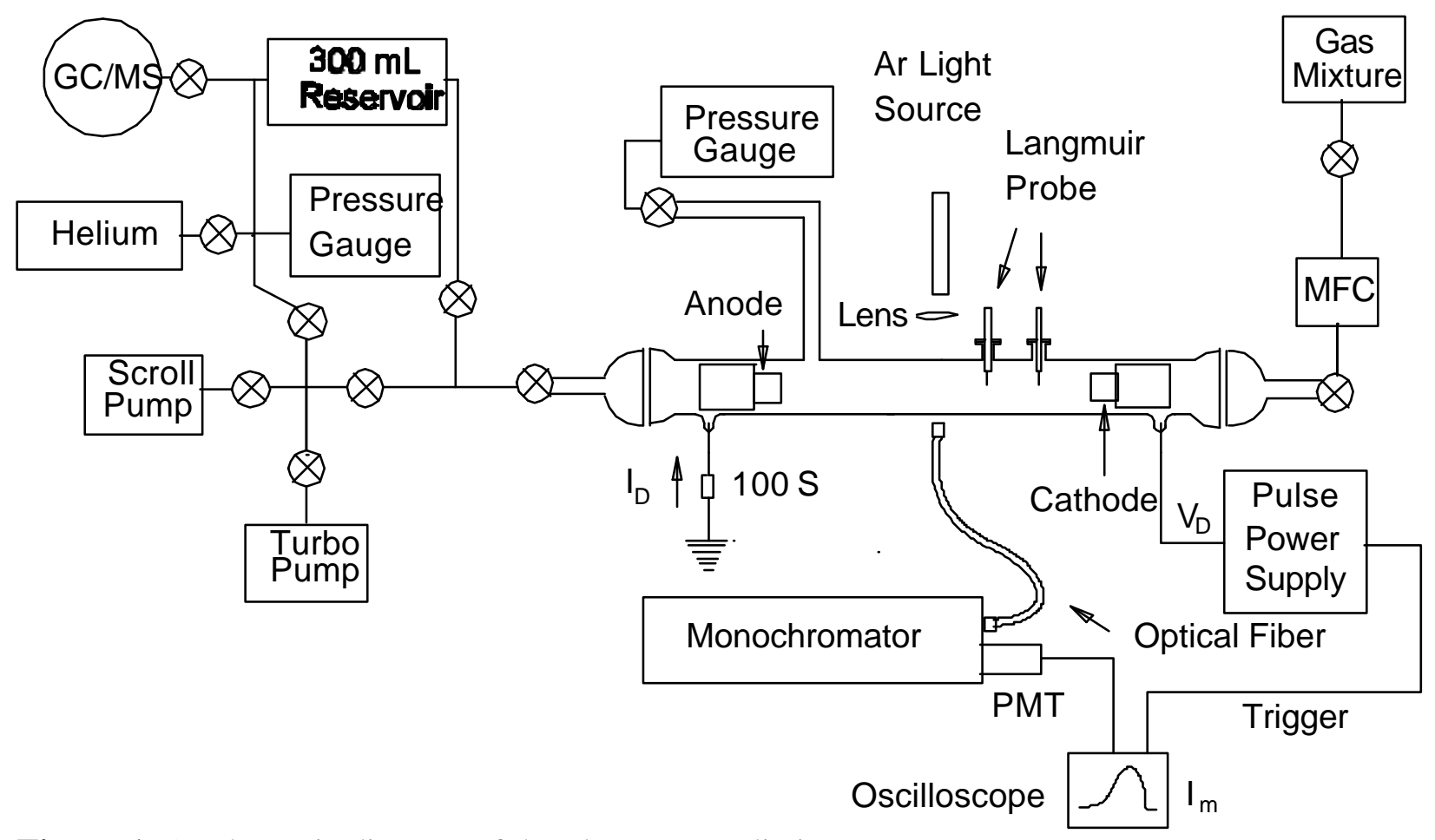

Figure 1. A schematic diagram of the plasma remediation apparatus. 
in [2]. The concentration of the target gas (benzene or methylene chloride) at the output of the reactor was monitored using a Hewlett-Packard 5970B GC-MS system; a new analytical method had to be developed in order to monitor the low pressure (below 10 Torr) output from the reactor [29]. Spectroscopic measurements (for the pulsed discharge experiments [15]) were conducted using a Jarrel-Ash model 82-000 Series 0.5 meter Ebert monochromator.

In the initial studies, dilute mixtures of benzene and methylene chloride in inert gas were used. By studying the destruction efficiency as a function of the gas pressure, flow rate, and the energy input, we were able to confirm the active role of the metastable states of the inert gases in the destruction process. These conclusions were confirmed by the basic electron attachment studies conducted in the plasma mixing apparatus described in the previous section $[16,17]$. While the DC glow discharge experiments [2] yielded destruction efficiencies that were comparable to the values

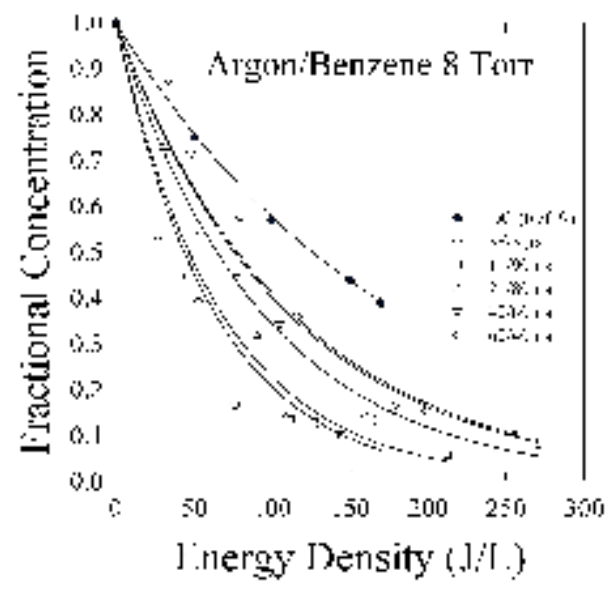

Figure 2. Plots of fractional concentration versus energy density for various pulse widths and for DC operation [15]. reported in the other low temperature plasma techniques, the pulsed discharge experiments [15] yielded even better destruction efficiencies. The destruction efficiency as a function of the pulse width is shown in Fig. 2 for a benzene/Ar mixture; for comparison, the data for a DC discharge [2] are also shown.

It is interesting to see that the destruction efficiency is enhanced as the pulse width is decreased (the pulse repetition rate was kept constant). This is the key to the energy efficiency, and can be understood as optimization of inert gas metastable formation. For a given energy density delivered to the plasma for a fixed frequency, narrow pulse width means high discharge voltage and current; the high energy electrons thus 
produced enhanced the formation of metastable atoms. Narrow pulse width also limited further heating

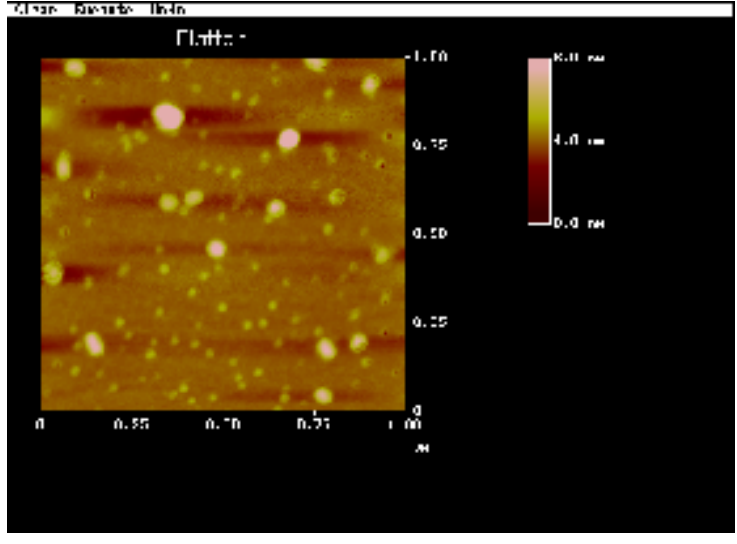

Figure 3. A $1 \mu \mathrm{m} \times 1 \mu \mathrm{m}$ image of the dust particles from an Ar/benzene glow discharge taken by an Atomic Force Microscope. of the electrons. By terminating the discharge before the electrons were further heated, one can maintain the metastable density without further energy input. (Furthermore, electron attachment is optimized for low energy electrons). In the offcycle of the pulsed discharge, metastable atoms transferred their energy to the benzene molecules. Therefore, narrow pulse width led to a better destruction efficiency.

Even more interesting was the fact that we $\underline{\text { could not detect any hazardous gaseous byproducts }}$

at the reactor output (in the DC or pulsed discharges) within our detection limits [15]. This is in contrast to the observation of phosgene and other hazardous byproducts at the output of reactors using other low-temperature plasma processes; see, for example, [30, 31]. Instead we observed dust particles in the reactor, mainly on the cathode. We have conducted several studies to identify the characteristics of these particles produced by a benzene discharge. Raman spectroscopic studies indicated that the particles were mainly carbon. They were also examined using a multimode NanoScope III Atomic Force Microscope (AFM) by the ORNL Nanoscale Science and Devices Group, and revealed that they consist of nanoparticles with sizes predominantly in the range of 1 to $10 \mathrm{~nm}$. (In these studies, the dust was shaken in toluene, and a drop containing suspended particles was placed on a freshly cleaved mica for viewing with AFM). An example of such a AFM scan of dust generated by a Ar/benzene mixture is shown in Fig. 7.

The high-efficiency of destruction and the formation of dust are both consistent with our basic mechanism of molecular dissociation via electron attachment to high-Rydberg states. For example, our basic studies on benzene have shown that extremely large cross sections are associated with this electron attachment process [27] and that a wide variety of negative ions are produced with high 
efficiency [32, 33]. As discussed in Section 3.3.3 (p. 21), these negative ions in turn act as precursors for the dust formation.

While we have clarified some of the basic mechanisms and illustrated the possibilities of the new technique further studies are needed to (i) fully understand the basic mechanisms (and thus to optimize the destruction process), and (ii) to generalize the destruction process.

It took us a considerable amount of time to set up the apparatuses from ground zero, and to establish the experimental techniques (this is evident in the publication list below). Now, we are in a unique position to expediently conduct both the basic and remediation experiments proposed below.

\section{RELEVANCE, IMPACT, AND TECHNOLOGY TRANSFER}

This project could provide long range solutions to the EM needs in two areas. In addition, the basic knowledge gained from this project can have important implications for other plasma-based applications. Two patent disclosures on possible technologies have been accepted by the ORNL Office of Technology Transfer for future filing.

\section{a. Treatment of highly-contaminated water or soil}

Ground water and soil contamination is a problem at almost all DOE waste sites. Air (or $\mathrm{N}_{2}$ ) stripping is currently being used where the subsequent removal of the contaminants, such as dense non- acqueous phase liquids (DNAPLs) and volatile organic compounds (VOCs), from the air stream is achieved by passive methods such as activated carbon, chemicals, or by bioremediation. These techniques may be suitable for weakly-contaminated water or soil, since the air stream will have only parts per million (ppm) levels of the contaminant. However, for highly-contaminated water or soil the purification of the contaminants in the air stream (up to several percent) by the above methods may not be practical or may be too slow. 
For example, air stripping followed by carbon absorption is used for the remediation of trichloroethylene (TCE) at the Paducah site. Here, the concentration of the TCE in the air stream is about 3 ppm [34]. The site has areas with highly-concentrated TCE in water, and plans for the remediation are just getting underway, and a draft proposal is expected in about three years. If our studies are successful, this will be a perfect application. The Oak Ridge Y-12 site is also using carbon sorption for the remediation of air streams associated with ground water treatment; they have indicated an interest in our technology.

Another general example would be a plume of organic liquid forming beneath a leaking underground storage tank. This behavior is typical of a heavy organic solvent such as trichloroethylene (TCE).

\section{b. Secondary Stage of a Thermal Incinerator}

The first stage of an incinerator burns highly-concentrated contaminants to a level of a few percent. Most of the present facilities also use a second incinerator, operated in tandem, to bring the contaminant to levels suitable for release in the atmosphere. However, this second stage thermal burning is not cost effective: energy is wasted when the background (carrier) gases, such as $\mathrm{N}_{2}$ and $\mathrm{O}_{2}$, are heated (and decomposed).

The studies conducted so far indicate that our technology has promise for both of the above applications. The project is closer to the application stage in the case a. above. As described in Section C, our studies so far have used one of the inert gases as the carries gas. Since it may be possible to recycle the carrier gas, it may be possible to use an inert gas to strip the contaminated soil or water, and then to use our plasma chemical process to remediate the contaminated gas stream.

In order to apply the technology in the case b. above, we need to conduct studies using air as the carrier gas in order to determine whether the basic characteristics remain the same compared to the studies using inert gases as the carrier. Retrofitting existing facilities may not provide short-term 
economic benefits. However, our method (if proven to be successful) can be incorporated in the facilities that may built in the future, such as the one that is being planned for the Advanced Mixed Waste Treatment Project (AMWTP) at the Idaho National Engineering and Environmental Laboratory.

\section{c. Enhancement of Basic Knowledge on Low-Temperature Plasmas}

This project has advanced the basic understanding of low-temperature plasmas. Specifically, we have provided evidence for the importance of Rydberg states in such plasmas [16, 18, 22, 35], which is likely to have far reaching implications for a variety of fields of research: several examples are, (i) hydrogen discharges used to generate $\mathrm{H}^{-}$beams for fusion energy research, (ii) plasma processing in semiconductor industry, and (iii) astrophysical plasmas. The main reason is the extremely large cross cross sections associated with the interactions of Rydberg states with charged particles, as clearly illustrated during the course of this project in the past three years. The PI has been recently invited to give a plenary talk entitled, "Electron Attachment to Rydberg States and Its Implications for Low-Temperature Plasmas," at the upcoming 53 ${ }^{\text {rd }}$ Annual Gaseous Electronics Conference in Houston, Texas.

\section{E. PROJECT PRODUCTIVITY}

This project was based on a new discovery in a basic research program conducted since the late 1980's at ORNL, i.e., that extremely large cross sections are associated with dissociative electron attachment to highly-excited states of molecules. That discovery was made in basic studies on electron attachment to laser excited molecules. However, laser excitation is not a cost effective method of achieving molecular excitation. In 1996, we proposed to investigate two discharge-based method for achieving molecular excitation and subsequent dissociative electron attachment. This was a classic case of transition from a basic research finding to an application. 
It took us a considerable amount of time to set up the apparatuses from ground zero, and to establish the experimental techniques for testing our ideas. Most of our achievements came in the last year of the project (this is evident in the publication list in Section G). We have achieved the main goals of establishing the viability of our proposed techniques for achieving molecular dissociation. In addition, we have discovered an unanticipated effect: there were no hazardous gaseous byproducts. We have conducted studies to show that the initial contaminants were converted to dust particles, and that this dust formation has origins in the negative ions produced via the enhanced dissociative electron attachment process. While further studies are needed to optimize and generalize these techniques, we have laid down a strong foundation for a promising new technology for the remediation of dilute toxic gas streams.

\section{F. PERSONNEL ASSOCIATED WITH THE PROJECT}

Lal A. Pinnaduwage, Senior Scientist, Oak Ridge National Laboratory

Cheung-Yu Ma, Research Staff Member, Oak Ridge National Laboratory

Dennis L. McCorkle, Research Associate Professor, University of Tennessee, Knoxville

Weixing Ding, Postdoctoral Fellow, Oak Ridge Associated Universities

Cumali Tav, Graduate Student, University of Tennessee, Knoxville 


\section{G. PUBLICATIONS}

a. Peer-Reviewed Publications

1. L. A. Pinnaduwage, W. Ding, and D. L. McCorkle,

"Enhanced Electron Attachment to Highly Excited Molecules Using a Plasma Mixing Scheme”, Appl. Phys. Lett. 71, 3634 (1997).

3. W. Ding, D. L. McCorkle, and L. A. Pinnaduwage,

"Enhanced Negative Ion Formation by Electron Attachment to Highly-Excited Molecules in a Flowing Plasma", J. Appl. Phys. 84, 3051 (1998).

4. D. L. McCorkle, W. Ding, C. Y. Ma, and L. A. Pinnaduwage,

"Exploratory Studies on a Plasma Remediation Process Based on Enhanced Dissociative Electron Attachment to Highly-Excited Molecules", J. Phys. D , 32, 46 (1999).

5. L. A. Pinnaduwage, W. Ding, D. L. McCorkle, S. H. Lin, A. M. Mebel, and A. Garscadden, "Enhanced Electron Attachment to Rydberg States in Molecular Hydrogen Volume Discharges", J. Appl. Phys., 85, 7064 (1999).

6. C. Y. Ma, D. L. McCorkle, W. Ding, and L. A. Pinnaduwage,

"A Methodology for Direct Sampling and Gas Chromatographic/Mass Spectral Analysis of Volatile Organic Compounds Emerging from a Low Pressure, Flow-Through Reaction Cell”, J. Chromatography A, 844, 217 (1999).

7. L. A. Pinnaduwage, C. Tav, D. L. McCorkle, and W. Ding, "Temperature Dependence of Electron Attachment to Methylene Chloride", J. Chem. Phys. , 110, 9011 (1999).

8. W. Ding, L. A. Pinnaduwage, C. Tav, and D. L. McCorkle, "The Role of High Rydberg States in Enhanced O- Formation in a Pulsed $\mathrm{O}_{2}$ Discharge", Plasma Sources Sci. Technol.. 8, 384 (1999).

9. D. L. McCorkle, W. X. Ding, C. Y. Ma, and L. A. Pinnaduwage, 
"Dessociation of Benzene in a Pulsed Glow Discharge", J. Appl. Phys. 86, 3550 (1999).

10. C. Tav and L. A. Pinnaduwage,

"Enhanced Dissociative Electron Attachment to Laser-Excited Benzene", submitted to J. Phys. D: Applied Physics (2000).

11. D. L. McCorkle, W. X. Ding, and L. A. Pinnaduwage,

"Remediation of Benzene in a Pulsed Glow Discharge: Byproduct Analysis and Dust Formation", to be submitted to J. Appl. Phys. (2000).

\section{b. Full Papers Published in Conference Proceedings:}

1. L. A. Pinnaduwage,

"Implications of Electron Attachment to Highly-Excited States in Pulsed Power Discharges", Digest of Technical Papers of the $11^{\text {th }}$ IEEE Pulsed Power Conference, (Eds. G. Cooperstein and I. Vitkovitsky) IEEE Publishing Services, New York, 1997. pp. 1048-1053.

2. L. A, Pinnaduwage, P. G. Datskos, W. X. Ding, and D. L. McCorkle,

"Enhanced Electron Attachment to Highly-Excited States of Molecules: Implications for Plasma Processing Discharges”, Proceedings of the 1998 International Congress on Plasma Physics, Ed. By P. Pavlo, pp. 125-128 (1999).

3. L. A, Pinnaduwage, W. X. Ding, and D. L. McCorkle,

"Enhanced Electron Attachment to Superexcited Rydberg States of Molecular Hydrogen Using a Plasma Mixing Scheme”, Proceedings of the 1998 International Congress on Plasma Physics, Ed. By P. Pavlo, pp. 129-132 (1999).

4. L. A. Pinnaduwage, W. X. Ding, D. L. McCorkle, and C. Y. Ma, "Enhanced Electron Attachment to Highly-Excited Molecules and Its Applications in Pulsed Plasmas”, Digest of Technical Papers of the $12^{\text {th }}$ IEEE Pulsed Power Conference, IEEE Publishing Services, New York, C. Stallings and H. Kirbie, Eds. pp. 1322-1325 (1999). 


\section{H. INTERACTIONS}

1. D. L. McCorkle and L. A. Pinnaduwage, "Enhanced Electron Attachment to Highly-Excited Molecules Using a Plasma Mixing Scheme", 49th Annual Gaseous Electronics Conference, Chicago, Illinois, October 20-24, 1996.

2. L. A. Pinnaduwage, "Implications of Electron Attachment to Highly-Excited States in Pulsed Power Discharges", $11^{\text {th }}$ IEEE Pulsed Power Conference, Baltimore, Maryland, June 29- July 2, 1997.

3. D. L. McCorkle and L. A. Pinnaduwage, "Destruction of $\mathrm{CH}_{2} \mathrm{Cl}_{2}$ Using a Glow Discharge Scheme", $50^{\text {th }}$ Annual Gaseous Electronics Conference, Madison, Wisconsin, October 6-9, 1997.

4. C. Y. Ma, D. L. McCorkle, W. X. Ding, and L. A. Pinnaduwage, "Methodology for Direct Sampling of Volatile Organic Compounds Emerging from a Low Pressure, Flow Through Reaction Cell for Subsequent GC/MS Analysis", presented at the 46th ASMS Conference on Mass Spectrometry and Allied Topics, Orlando, Florida, May 31- June 4, 1998.

5. W. X. Ding, D. L. McCorkle, and L. A, Pinnaduwage, "Enhanced Radical Formation by Electron Attachment to Highly-Excited States of Molecules in Plasmas", presented at the $25^{\text {th }}$ IEEE International Conference on Plasma Science, Raleigh, North Carolina, June 1-4, 1998.

6. W. X. Ding, D. L. McCorkle, and L. A, Pinnaduwage, "Decomposition of Volatile Organic Compounds in a Positive Column Glow Discharge Plasma", presented at the $25^{\text {th }}$ IEEE International Conference on Plasma Science, Raleigh, North Carolina, June 1-4, 1998.

7. L. A. Pinnaduwage, "A Novel Energy-Efficient Plasma Chemical Process for the Destruction of Volatile Toxic Compounds", presented at the Environmental Management Science Program Workshop, Chicago, IL, July 27-30, 1998.

8. L. A, Pinnaduwage, P. G. Datskos, W. X. Ding, and D. L. McCorkle, "Enhanced Electron Attachment to Highly-Excited States of Molecules: Implications for Plasma Processing Discharges", presented at the 1998 International Congress on Plasma Physics, Prague, Czech 
Republic, June 27- July 3, 1998.

9. L. A, Pinnaduwage, W. X. Ding, and D. L. McCorkle, "Enhanced Electron Attachment to Superexcited Rydberg States of Molecular Hydrogen Using a Plasma Mixing Scheme", presented at the 1998 International Congress on Plasma Physics, Prague, Czech Republic, June 27- July 3, 1998.

10. L. A, Pinnaduwage, W. X. Ding, and D. L. McCorkle, "Enhanced Electron Attachment to Rydberg States in Molecular Hydrogen Volume Discharges", presented at the 1999 Centennial Meeting of the American Physical Society, March 20-26, Atlanta, GA, 1999.

11. W. X. Ding, L. A, Pinnaduwage, C. Tav, and D. L. McCorkle, "O- Formation by Electron Attachment to High Rydberg States", presented at the 1999 Centennial Meeting of the American Physical Society, March 20-26, Atlanta, GA, 1999.

12. L. A. Pinnaduwage, W. X. Ding, D. L. McCorkle, and C. Y. Ma, "Implications of Electron Attachment to Highly-Excited States of Molecules and Its Applications in Pulsed Plasmas", $12^{\text {th }}$ IEEE Pulsed Power Conference, Monterey, California, June 27- June 30, 1999.

13. L. A. Pinnaduwage, "Novel Plasma Chemical Process for the Destruction of Volatile Toxic Compounds", DOE Environmental Management Science Program Workshop, Oak Ridge, Tennessee, September 22, 1999.

14. W. Ding, D. L. McCorkle, C. Y. Ma, and L. A. Pinnaduwage, "Dissociation of Benzene in a Pulsed Glow Discharge", 52 ${ }^{\text {nd }}$ Annual Gaseous Electronics Conference, Norfolk, Virginia, October 5-8, 1999.

15. C. Tav and L. A. Pinnaduwage, "Dissociative Electron Attachment to Laser-Excited Benzene", $52^{\text {nd }}$ Annual Gaseous Electronics Conference, Norfolk, Virginia, October 5-8, 1999.

16. L. A. Pinnaduwage, W. Ding, and D. L. McCorkle, "Negative Ion Formation in Pulsed Plasmas", $52^{\text {nd }}$ Annual Gaseous Electronics Conference, Norfolk, Virginia, October 5-8, 1999.

17. L. A. Pinnaduwage, C. Y. Ma, D. L McCorkle, and W. X. Ding, “A Novel Energy-Efficient Plasma Chemical Process for the Destruction of Volatile Toxic Compounds", presented at the Environmental Management Science Program Workshop, Atlanta, GA, April 24-28, 2000. 
18. "Electron Attachment to Rydberg States and Its Implications for Low-Temperature Plasmas", L. A. Pinnaduwage, $53^{\text {rd }}$ Annual Gaseous Electronics Conference, Houston, Texas, October 24-27, 2000 (INVITED).

\section{TRANSITIONS}

This technology is not yet at a stage where it can be used in the field. As we described in Section $\mathrm{B}$, this project was based on a new discovery in basic research and the transition to field usage will take a few more years.

\section{J. PATENT DISCLOSURES}

1. L. A. Pinnaduwage, C. Y. Ma, D. L. McCorkle, and W. Ding, "A Glow Discharge Method for the Destruction of Low-Concentrations of Volatile Toxic Compounds", patent disclosure elected to be filed by the ORNL Technology Transfer Office, 1998.

2. L. A. Pinnaduwage, W. Ding, and D. L. McCorkle, "A Plasma Mixing Method and Device for Plasma Processing of Materials", patent disclosure elected to be filed by the ORNL Technology Transfer Office, 1999. 


\section{K. FUTURE WORK}

Further research is needed to bring this project to a stage where it can be used in the field. Research is needed to be conducted to further our understanding of the role played by the Rydberg states in discharge plasmas (to use that knowledge in optimizing the destruction process), and to test the destruction scheme on a variety of pollutants of interest to the EMSP program under realistic conditions (process generalization). The work that needs to be done has been described in detail in the grant renewal proposal that was submitted in January, 2000. The main research tasks are,

é Conduct microwave experiments to quantify the Rydberg state number densities in glow discharges under various experimental conditions, and to accurately determine the electron density in the discharge for modeling the destruction process.

é Optimize the destruction process using the knowledge gained from the above studies for the destruction of benzene and methylene chloride in Ar and air carrier gases.

é Test the optimized destruction process on other pollutants of interest to the EMSP program, such as trichloroethylene, carbontetrachloride, and dioxins.

é Further investigate the nanoparticle production in the destruction apparatus, and investigate the chemical properties of the nanoparticles. 


\section{LITERATURE CITED}

1. Penetrante, B. M. and Schultheis, S. E., eds. Nonthermal Plasma Technologies for Pollution Control. NATO ASI series. Vol. 34, Parts A and B, Springer-Verlag: Berlin (1993).

2. McCorkle, D. M., Ding, W. X., Ma, C. Y., and Pinnaduwage, L. A., "Dissociation of Benzene and Methylene Chloride Based on Enhanced Dissociative Electron Attachment to Highly-Excited Molecules", J. Phys. D, 32, 46 (1999).

3. Pinnaduwage, L. A. and Datskos, P. G., "A Novel Technique for Real-Time Monitoring of Electron Attachment to Laser-Excited Molecules", J. Chem. Phys., 104, 8382 (1996).

4. Pinnaduwage, L. A. and McCorkle, D. L., "Mass Identification of Negative Ions in Excimer-LaserIrradiated Triethylamine: Atomic Rearrangements in Electron Attachment to Highly-Excited States", Chem. Phys. Lett., 255, 410 (1996).

5. Pinnaduwage, L. A. and Christophorou, L. G., "H- Formation in Laser-Excited Molecular Hydrogen", Phys. Rev. Lett., 70, 754 (1993).

6. Pinnaduwage, L. A., Christophorou, L. G., and Bitouni, A. P., "Enhanced Electron Attachment to Superexcited States of Saturated Tertiary Amines", J. Chem. Phys., 95, 274 (1991).

7. Delcroix, J. L., Ferreira, C. M., and Ricard, A., "Metastable Atoms and Molecules in Ionized Gases", in Principles of Laser Plasmas, G. Bakefi, Editor. 1976, Wiley: New York. p. 159.

8. Kolts, J. H. and Setser, D. W., "Electronically-Excited Long-Lived States of Atoms and Diatomic Molecules in Flow Systems", in Reactive Intermediates in the Gas Phase, D. W. Setser, Editor. 1979, Academic Press: New York.

9. Trajmar, S. and Nickel, J. C., "Cross-Section Measurements for Electron Impact on Excited ATomic Species", in Advances in Atomic, Molecular, and Optical Physics, D. Bates and B. Bederson, Editors. 1993, Academic Press, Inc.: New York. p. 45.

10. Johnston, M., Fujii, K., Nickel, J., and Trajmar, S., "Ionization of Metastable Neon By Electron Impact", J. Phys. B, 29, 531 (1996).

11. Piper, L. G., Richardson, W. C., Taylor, G. W., and Setser, D. W., "Quenching Processes and Rate Constants for Interaction of Metastable Argon Atoms with Diatomic and Triatomic Molecules", Discussions of the Faraday Society, 53, 100 (1972). 
12. Bourene, M. and Calve, J. L., "De-Excitation Cross Sections of Metastable Argon by Various Atoms and Molecules", J. Chem. Phys., 58, 1452 (1973).

13. Rosenstock, H. M., Draxl, K., Steiner, B. W., and Herron, J. T., "Energetics of Gaseous Ions", Journal of Physical and Chemical Reference Data, 6 (supplement No. 1), I1 (1977).

14. Elias, S. G., Bartmess, J. E., Lebman, J. F., Holmes, J. L., Levine, R. D., and Mallard, W. G., "Gas-Phase Ion and Neutral Chemistry", J. Phys. Chem. Ref. Data, 17, (1988).

15. McCorkle, D. M., Ding, W. X., Ma, C. Y., and Pinnaduwage, L. A., "Dissociation of Benzene in a Pulsed Glow Discharge", Journal of Applied Physics, 86, 3550 (1999).

16. Pinnaduwage, L. A., Ding, W., and McCorkle, D. M., "Enhanced Electron Attachment to HighlyExcited Molecules Using a Plasma Mixing Scheme", Appl. Phys. Lett., 71, 3634 (1997).

17. Ding, W. X., McCorkle, D. M., and Pinnaduwage, L. A., "Enhanced Formation of Negative Ions by Electron Attachment to Highly-Excited Molecules in a Flowing Afterglow Plasma", Journal of Applied Physics, 84, 3051 (1998).

18. Pinnaduwage, L. A., Ding, W. X., McCorkle, D. M., Lin, S. H., Mebel, A. M., and Garscadden, A., "Enhanced Electron Attachment to Rydberg States in Molecular Hydrogen Discharges", Journal of Applied Physics, 85, 7064 (1999).

19. Pinnaduwage, L. A., "Comment on "Effect of Electron Temperature on Negative Hydrogen Ion Production in a Low-Pressure Ar Discharge Plasma with Methane" [Appl. Phys. Lett. 63, 1619 (1993)", Appl. Phys. Lett., 67, 1034 (1995).

20. Iizuka, S., Koizumi, T., Takada, T., and Sato, N., "Effect of Electron Temperature on Negative Hydrogen Ion Production in a Low-Pressure Ar Discharge Plasma with Methane", Appl. Phys. Lett., 63, 1619 (1993).

21. Iizuka, S., Takada, T., and Sato, N., "Enhanced Methyl Radical Production in an Ar/CH4 PinHollow Cathode Discharge", Appl. Phys. Lett., 64, 1786 (1994).

22. Ding, W. X., Pinnaduwage, L. A., Tav, C., and McCorkle, D. M., "The Role of High-Rydberg States in Enhanced O - Formation in a Pulsed $\mathrm{O}_{2}$ Discharge", Plasma Sources Sci. Technol., 8, 384 (1999).

23. DeCorpo, J. J. "Correlation of Excess Energies of Dissociative Electron Attachment Processes with the Translational Energies of Their Products", J. Chem. Phys., 54, 1592 (1971). 
24. Christodoulides, A. A. and Christophorou, L. G., "Electron Attachment to Brominated Aliphatic Hydrocarbons of the Form $n-\mathrm{C}_{\mathrm{N}} \mathrm{H}_{2 \mathrm{~N}+1} \mathrm{Br}(\mathrm{N}=1-6,8$, and 10). I. An Electron Swarm Study", J. Chem. Phys., 54, 4691 (1971).

25. Chu, S. C. and Burrow, P. D., "Dissociative Attachment of Electrons in the Chloromethanes", Chem. Phys. Lett., 172, 17 (1990).

26. Aflatooni, K., Gallup, G. A., and Burrow, P. D., "Dissociative Electron Attachment in Chloroalkanes and the Correlation with Vertical Attachment Energies", Chem. Phys. Lett., 282, 398 (1998).

27. Tav, C. and Pinnaduwage, L. A., "Enhanced Dissociative Electron Attachment to Laser-Excited Benzene", Journal of Physics D: Applied Physics, submitted (2000).

28. Pinnaduwage, L. A. and Tav, C., "Temperature Dependence of Electron Attachment to Methylene Chloride", J. Chem. Phys., 110, 9011 (1999).

29. Ma, C. Y., McCorkle, D. M., Ding, W., and Pinnaduwage, L. A., "Methodology for Gas Chromatographic- Mass Spectral Analysis of Volatile Organic Compounds Emerging from a Low Pressure, Flow-Through Reaction Cell", J. Chromatography. A, 844, 217 (1999).

30. Vitale, S. A., Hadidi, K., Cohn, D. R., Bromberg, L., and Falkos, P., "Decomposing VOCs With an Electron Beam Plasma Reactor", Chemtec, April, 58 (1995).

31. Hsiao, M. C., Merritt, B. T., Penetrante, B. M., Vogtlin, G. E., and Wallman, P. H., "PlasmaAssisted Decomposition of Methanol and Trichloroethylene in Atmospheric Pressure Air Streams by Electrical Discharge Processing", Journal of Applied Physics, 78, 3451 (1995).

32. Pinnaduwage, L. A., Nagesha, K., Zhu, Y., Buchanan, M. V., and Hurst, G. B., "LaserEnhanced Negative Ion Mass Spectrometry for Weakly-Electron-Attaching Species", Int. J. Mass Spectrom. Ion Processes, 193, 77 (1999).

33. Nagesha, K. and Pinnaduwage, L. A., "Magnetic and Electric Field Induced Enhancements in Laser Induced Anion Formation", Chem. Phys. Lett., 312, 19 (1999).

34. Richards, W., Personal communication (2000).

35. Pinnaduwage, L. A. "Electron Attachment to Rydberg States and Its Implications for LowTemperature Plasmas", (Invited talk) to be presented at the Gaseous Electronics Conference Houston, TX (October 2000). 